\title{
Colorimetric Point-of-Care Detection of Clostridium tyrobutyricum Spores in Milk Samples
}

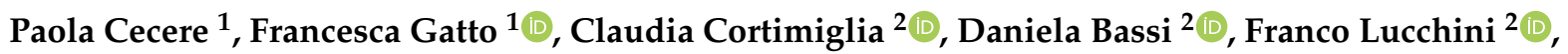 \\ Pier Sandro Cocconcelli ${ }^{2}$ and Pier Paolo Pompa ${ }^{1, *}$ \\ 1 Nanobiointeractions \& Nanodiagnostics, Istituto Italiano di Tecnologia (IIT), 16163 Genova, Italy; \\ paola.cecere@iit.it (P.C.); francesca.gatto@iit.it (F.G.) \\ 2 Dipartimento di Scienze e Tecnologie Alimentari per la Sostenibilità della Filiera Agro-Alimentare, \\ Facoltà di Scienze Agrarie Alimentari ed Ambientali, Università Cattolica del Sacro Cuore, \\ Via Emilia Parmense 84, 29122 Piacenza-Cremona, Italy; claudia.cortimiglia@unicatt.it (C.C.); \\ daniela.bassi@unicatt.it (D.B.); franco.lucchini@unicatt.it (F.L.); pier.cocconcelli@unicatt.it (P.S.C.) \\ * Correspondence: pierpaolo.pompa@iit.it
}

check for

updates

Citation: Cecere, P.; Gatto, F.; Cortimiglia, C.; Bassi, D.; Lucchini, F.; Cocconcelli, P.S.; Pompa, P.P.

Colorimetric Point-of-Care Detection of Clostridium tyrobutyricum Spores in Milk Samples. Biosensors 2021, 11, 293 https://doi.org/10.3390/bios11090293

Received: 26 July 2021

Accepted: 20 August 2021

Published: 24 August 2021

Publisher's Note: MDPI stays neutral with regard to jurisdictional claims in published maps and institutional affiliations.

Copyright: (c) 2021 by the authors. Licensee MDPI, Basel, Switzerland This article is an open access article distributed under the terms and conditions of the Creative Commons Attribution (CC BY) license (https:// creativecommons.org/licenses/by/ $4.0 /)$.

\begin{abstract}
Clostridium tyrobutyricum represents the main spoiling agent responsible for late blowing defects (LBD) in hard and semi-hard cheeses. Its spores are resistant to manufacturing procedures and can germinate during the long ripening process, causing the burst of the cheese paste with a consequent undesirable taste. The lower quality of blown cheeses leads to considerable financial losses for the producers. The early identification of spore contaminations in raw milk samples thus assumes a pivotal role in industrial quality control. Herein, we developed a point of care (POC) testing method for the sensitive detection of $C$. tyrobutyricum in milk samples, combining fast DNA extraction (with no purification steps) with a robust colorimetric loop-mediated isothermal amplification (LAMP) technique. Our approach allows for the sensitive and specific detection of C. tyrobutyricum spores (limit of detection, LoD: $\sim 2$ spores $/ \mathrm{mL}$ ), with the advantage of a clear nakedeye visualization of the results and a potential semi-quantitative discrimination of the contamination level. In addition, we demonstrated the feasibility of this strategy using a portable battery-operated device that allowed both DNA extraction and amplification steps, proving its potential for onsite quality control applications without the requirement of sophisticated instrumentation and trained personnel.
\end{abstract}

Keywords: Clostridium tyrobutyricum; spores; LAMP; point-of-care; colorimetric test; milk

\section{Introduction}

The contamination of milk by endospores represents a critical issue for industrial quality control in the production of hard and semi-hard cheese, such as Grana Padano, Parmigiano Reggiano, Emmental, and Gouda. Although milk does not provide suitable growth conditions, long ripening times characteristic of these cheeses may create favorable anaerobic conditions for the germination of spores in vegetative cells [1]. The resulting metabolic activity leads to pronounced cheese spoilage defects. Late blowing is one of the most frequent problems still affecting hard cheese production in the dairy industry. Such spoilage is characterized by butyric fermentation of lactate achieved by the vegetative cells, leading to the production of butyric acid, acetic acid, hydrogen, and carbon dioxide [2,3]. As a consequence, late blowing results in the burst of the cheese load, generation of several heterogeneously distributed cavities (corresponding to the volumes of gas produced and mass digested), and a resulting undesirable taste. The lower sensory quality of blown cheeses leads to significant financial losses for producers [4]. Among spore-forming anaerobic bacteria, butyric acid-producing clostridia are considered the main agents of such damages, due to their spore-surviving attitude during whole-cheese manufacturing including heat treatments [5-11]. Several clostridial species, mainly Clostridium tyrobutyricum, 
Clostridium butyricum, Clostridium sporogenes, and Clostridium beijerinckii, have been isolated from blown cheese $[9,10,12-14]$. In particular, C. tyrobutyricum has been identified as the principal spoiling organism responsible for late blowing defects (LBD) $[7,9,15-21]$. The avoidance of such issue is challenging, due to the ubiquitous presence of Clostridium spores. The main sources of contamination are thought to be silage, water, and unhygienic animal bedding [22,23]. Moreover, although LBD occurs mostly in unpasteurized milk, even pasteurized milk cheeses may be affected.

Several approaches have been proposed to prevent clostridia spoilage, including the use of additives [24], milk bactofugation or microfiltration [25,26], or the addition of lactic acid bacterial strains biologically active against Gram-positive bacteria [27-31]. However, most of these methods have technical or regulatory limitations. Traditionally, cow's milk is processed through consolidated manufacturing practices, which lead to the production of typical products registered as a Protected Designation of Origin cheeses (PDO, European Union). Preservatives like nitrate and lysozyme may be added to milk during cheese production, due to their capacity to selectively reduce the microorganism survival and multiplication [16,24,32,33]. Nitrate was commonly employed in Emmental production [34], but its use was banned after the decision of the European Food Safety Authority (EFSA) to reduce levels of nitrosamines in food products (EFSA, 2010). In Italy, lysozyme from egg is the only bacteriostatic agent allowed for the protection of raw cow's milk in Grana Padano cheese production. Its addition seemed to influence bacterial distribution in terms of Clostridium and Lactobacillus. In particular, C. tyrobutyricum was negatively affected by the presence of lysozyme [35].

The bacterial communities associated with the spoiled hard cheese have been studied through routine diagnostic methods, involving microbiological methods (most probable number (MPN) procedures), molecular approaches (PCR-based methods and Nextgeneration sequencing (NGS) technology), and immunological methods (immune-assays, flow cytometry) $[9,14,16,18,36,37]$. The identification of specific bacterial species using conventional cultivation methods is a long and difficult process, involving MPN counting and subsequent confirmation by checking the lactate fermentation capacity of cells from gas-positive samples [6,38]. This method is arduous for adapting to the needs of the production process, due to the requirement of several days for the identification of positive samples. Additionally, it is not possible to discriminate between the different species using specific media or phenotypic markers [39,40], and a series of further tests is frequently necessary.

To overcome these issues, different strategies for detecting species-specific DNA sequences of spoiling bacteria in milk have been devised. Currently, standard methods include DNA extraction from spores and its subsequent amplification using PCR or realtime PCR-based techniques $[7,35,36,41,42]$. However, the extraction of spore DNA from food matrices poses several limitations, starting from the necessity for long and multistep procedures. Indeed, to achieve an efficient lysis of spores, it is often necessary to combine the use of chemical buffers with the mechanical disruption of spores through bead beating or sonication, which requires extra instrumentation and specialized laboratories. In addition, an important issue is the common occurrence of false-negative results due to the presence of various food substances and chemicals used for the extraction that can inhibit the PCR reaction [30]. Furthermore, PCR-based techniques are still too costly for routine applications in the cheese industry, due to the need of specialized instrumentation and skills [4]. In this framework, the development of a rapid, effective, and low-cost method for on-site diagnostics would be of great importance.

In this work, we have developed a point-of-care (POC) molecular method to track contaminations of $C$. tyrobutyricum spores in milk samples. In particular, our test exploits a simple and direct DNA extraction step through the fast chemical lysis of spores in heating conditions, without the need for mechanical disruption and/or purification procedures, coupled to the spore detection through a colorimetric loop-mediated isothermal amplification (LAMP). The identification of contaminated samples was proven to be 
possible by a simple visual inspection, while achieving a highly sensitive, specific, and semi-quantitative detection. The feasibility of the entire process for on-site applications was demonstrated using a portable battery-operated heating device, suitable for both the lysis and the amplification steps.

\section{Materials and Methods}

\subsection{Clostridium tyrobutyricum Spore Preparation}

C. tyrobutyricum UC7086 from Università Cattolica Culture Collection (Piacenza, Cremona, Italy) was used for the development of the LAMP assay and for the milk artificial contamination to evaluate the performance of the method. C. tyrobutyricum spores were obtained using the protocol described by Bassi et al. [21]. Briefly, the strain was cultured in reinforced clostridial medium broth (RCM) (Oxoid, Altrincham, UK) and incubated at $37{ }^{\circ} \mathrm{C}$ in anaerobiosis. $1 \%$ of well-grown suspension was inoculated into a regenerated cellulose tubular membrane located in a bottle with $400 \mathrm{~mL}$ of RCM broth. After five days of anaerobiosis at $37^{\circ} \mathrm{C}$ and at least 15 days of aerobiosis, the membrane content was checked to verify the presence of a high percentage of spores by visualization with phase-contrast microscopy (Nikon, Tokio, Japan). Spores were then collected, washed several times with sterile distilled water, and purified using Percoll gradient (Merck KGaA, Darmstadt, Germany) as previously described [43]. No vegetative cells were observed at the phase-contrast microscopy. Purified spores were stocked at $-20{ }^{\circ} \mathrm{C}$. The spore counts were determined by plating 10-fold dilutions of the obtained spore solution after pasteurization for $10 \mathrm{~min}$ at $80^{\circ} \mathrm{C}$. The stock was used to develop the LAMP assay and to artificially inoculate milk samples.

\subsection{Artificial Contamination and Milk Samples Preparation}

Raw milk was collected and stored at $20^{\circ} \mathrm{C}$ before use. The volume was divided into aliquots of $20 \mathrm{~mL}$, which were inoculated with 1000, 100, and 10 spores. A negative control was also added consisting of milk without spores. Each sample was treated with $20 \mathrm{~mL}$ of Buffer F (EDTA 100 mM (Sigma-Aldrich, St. Louis, MO, USA), sodium citrate $250 \mathrm{mM}$ (Carlo Erba, Cornaredo, Italy), Tris HCl 200 mM (Sigma-Aldrich, St. Louis, MO, USA), Triton X-100 0.01\%; final pH 7.5 (Sigma-Aldrich, St. Louis, MO, USA)) and incubated in a water bath at $65^{\circ} \mathrm{C}$ for $1 \mathrm{~h}$. After that, samples were vortexed for $10 \mathrm{~s}$ and centrifuged at $13,000 \mathrm{rpm}$ for $30 \mathrm{~min}$ at $40{ }^{\circ} \mathrm{C}$. The supernatant was discarded, paying attention to avoid the mixing of pellets with the residual fat. The experiment was performed in triplicates. Moreover, an aliquot of each sample was analyzed to check the right number of recovered spores, through the plating of decimal dilutions on RCM agar (Oxoid, Altrincham, UK).

\subsection{Specificity and Sensitivity of LAMP Assay}

To determine the sensitivity of the assay, serial dilutions of the aqueous spore stock were prepared and tested by real-time fluorescent detection. To determine the specificity of the reaction, several relevant strains were used. In particular, two additional strains of C. tyrobutyricum (UC9037, UC9038) and different clostridial, namely C. sporogenes (UC9000) and C. butyricum (UC9034 and ATCC10702), and nonclostridial species commonly present in milk (Lactobacillus acidophilus UC8810, Lactobacillus rhamnosus UC8887, Lactobacillus reuteri UC8916, Lactobacillus sakei UC8577, Leuconostoc lactis UC8773, Lactococcus lactis MG1363, Lactobacillus plantarum UC8491, Escherichia coli UC4131) were selected for this purpose. Clostridium species were inoculated in RCM broth (Oxoid, Altrincham, UK) in anaerobiosis at $37^{\circ} \mathrm{C}$, Lactobacillus and Leuconostoc were cultivated in MRS broth (Oxoid, Altrincham, $\mathrm{UK}$ ) in anaerobiosis at $37^{\circ} \mathrm{C}$, E. coli was cultivated in LB broth (Oxoid, Altrincham, UK) in aerobiosis at $37^{\circ} \mathrm{C}$. The genomic DNA of these strains was extracted from pure culture using the EZNA bacterial DNA kit (Omega Bio-tek, GA, USA) following the manufacturer's instructions. 


\subsection{Rapid DNA Extraction}

The obtained pellets were resuspended in $100 \mu \mathrm{L}$ of lysis buffer (InstaGene ${ }^{\mathrm{TM}}$ Matrix, Bio-Rad, München, Germany) and briefly vortexed. The samples were then heated at $130{ }^{\circ} \mathrm{C}$ for $7 \mathrm{~min}$ in a prototypal battery-operated device. After $7 \mathrm{~min}$ incubation time, the samples were left to cool down for a few minutes and were directly processed in the LAMP reactions, with no purification steps.

\subsection{Primer Design}

LAMP primers were designed from the phosphotransacetylase ( $p t a)$ gene of Clostridium tyrobutyricum, and the univocal alignment was verified using the Basic Local Alignment Search Tool (BLAST). Primer sequences are reported in Table 1.

Table 1. Names and sequences of primers used in this study.

\begin{tabular}{|c|c|}
\hline Name & Sequence $\left(5^{\prime}-3^{\prime}\right)$ \\
\hline F3 & GAGAACTTCAATTGGATGCTTC \\
\hline B3 & TTGCAGCTTGTGCTTGTA \\
\hline FIP & AGGTCCTATTGCTTCCGCTTGCACCTGGTAGTCCTGTA \\
\hline BIP & TGTCAAGGCTTTGCAAAACCAACTGCTGTTACAGCTACTACATT \\
\hline LoopF & TTCCTGCTTGAAGTTCAGG \\
\hline LoopB & GAGGATGCAGTTCTGACGATAT \\
\hline
\end{tabular}

\subsection{LAMP Reactions for Real-Time Fluorescence Detection}

LAMP reactions were performed in a $25 \mu \mathrm{L}$ final volume using the protocol described by Cibecchini et al. [44] with the following modifications: $1.6 \mu \mathrm{M}$ of forward inner primer (FIP) and backward inner primer (BIP), $0.2 \mu \mathrm{M}$ of forward outer primer (F3) and backward outer primer (B3), $0.4 \mu \mathrm{M}$ of forward loop primer (LF) and backward loop primer (LB) (Integrated DNA Technologies, Coralville, IA, USA), and $10 \mu \mathrm{L}$ of DNA template. DNAfree LAMP reactions were included as negative controls. Real-time amplifications were conducted at $63{ }^{\circ} \mathrm{C}$ on the StepOne ${ }^{\mathrm{TM}}$ Applied Biosystem Real-Time PCR instrument (Thermo Fisher Scientific, Waltham, MA, USA) using the StepOne ${ }^{\mathrm{TM}}$ Software v2.3.

\subsection{LAMP Reactions for Colorimetric Assay}

LAMP colorimetric reactions were performed in a $50 \mu \mathrm{L}$ final volume following the protocol described by Cibecchini et al. [44] with some modifications: $1.6 \mu \mathrm{M}$ each of inner primers, $0.2 \mu \mathrm{M}$ each of outer primers, $0.4 \mu \mathrm{M}$ of loop primers (Integrated DNA Technologies, Coralville, IA, USA), and $20 \mu \mathrm{L}$ of DNA template. DNA-free LAMP reactions were included as negative controls. Colorimetric LAMP reactions were performed on a prototypal portable battery-operated device at $63^{\circ} \mathrm{C}$ for $1 \mathrm{~h}$, and the amplification efficiency was verified by the pink-to-yellow color change of the reaction mix.

\section{Results and Discussion}

The milk spoilage caused by $C$. tyrobutyricum represents a crucial issue in the field of cheese production, affecting long-ripened hard cheese losses. To address this concern, the present study focused on the design and development of a rapid POC method aimed at detecting the presence of $C$. tyrobutyricum spores in milk samples. The schematic workflow of the entire procedure is displayed in Figure 1. 


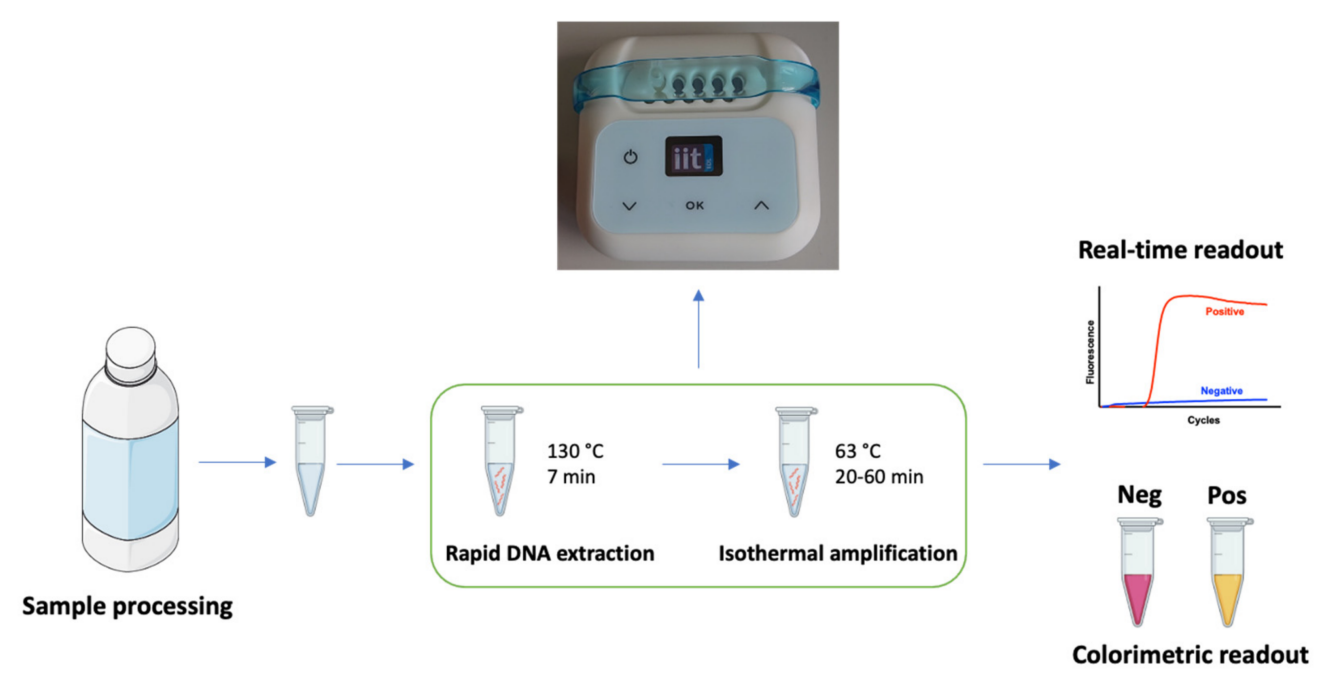

Figure 1. Schematic workflow of the POC process for C. tyrobutyricum identification. The method comprises three steps: milk sample processing, rapid DNA extraction performed at $130{ }^{\circ} \mathrm{C}$ for $7 \mathrm{~min}$, and DNA isothermal amplification performed at $63^{\circ} \mathrm{C}$ for $20-60 \mathrm{~min}$, with a fluorescent or naked-eye colorimetric readout.

Raw milk samples were artificially contaminated with C. tyrobutyricum spores obtained from pure culture. $20 \mathrm{~mL}$ spiked samples were centrifuged to obtain spore pellets. A rapid DNA extraction procedure was developed and optimized using a simple lysis buffer and a "super-heating" step (above $100{ }^{\circ} \mathrm{C}$ ), thus avoiding the complex mechanical lysis of the spores. The heating treatment was carried out by systematically investigating different operating temperatures, between 100 and $160^{\circ} \mathrm{C}$ with $5{ }^{\circ} \mathrm{C}$ increment steps, and different incubation times, in order to achieve optimal lysis conditions. Interestingly, when using $130^{\circ} \mathrm{C}$ heating conditions, we managed to achieve an efficient DNA extraction from the spore pellets in only $7 \mathrm{~min}$, a very convenient method for on-site quality control applications. Lower temperatures produced an incomplete lysis, whereas higher temperatures led to DNA degradation. The lysis procedure was also effectively performed using a basic prototypal battery-operated heating device.

The resulting solution was then directly used for the amplification phase, without any purification steps due to the robustness of the LAMP reaction and the absence of any inhibitor in the lysis buffer. An aliquot of the extracted DNA from the super-heating-treated tubes was directly added to the amplification mix.

To assess and optimize the efficiency of the lysis step and the sensitivity of the isothermal reaction, we performed preliminary experiments extracting $C$. tyrobutyricum spores dispersed in water. The real-time fluorimetric LAMP reaction showed a high sensitivity, demonstrating that the developed heating procedure guaranteed the efficient lysis of the samples. The method was proven to achieve an excellent limit of detection (LoD) as low as 2 spores/reaction and a very fast readout (ca. $20 \mathrm{~min}$ ), as reported in Figure 2. 


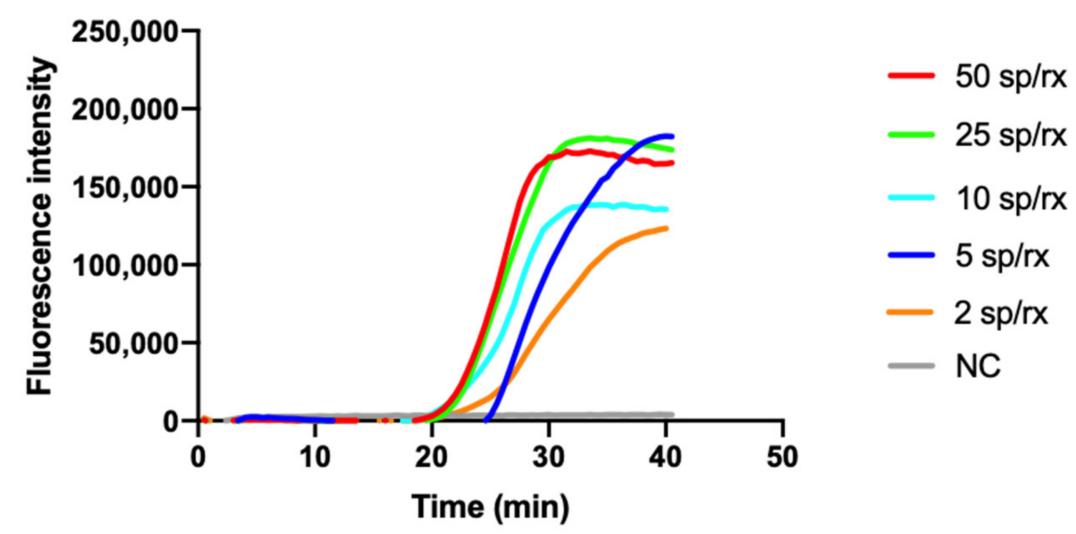

Figure 2. Representative SYBR Green-based real-time fluorescence detection of $C$. tyrobutyricum spores in water at decreasing concentrations of spores/reaction (sp/rx). NC: negative control. All experiments were performed in quadruplicate, each being repeated at least three times.

We then verified the specificity of the LAMP assay by testing the reaction with genomic DNA from different clostridia species (C. sporogenes and C. butyricum) and other nonclostridial species usually contaminating raw milk, namely Lactobacillus acidophilus, Lactobacillus rhamnosus, Lactobacillus reuteri, Lactobacillus sakei, Leuconostoc lactis, Lactococcus lactis, Lactobacillus sakei, Lactobacillus plantarum, and Escherichia coli. Interestingly, our technique was found to be highly specific, recognizing only the C. tyrobutyricum species, with no false positive results detected (Figure 3).

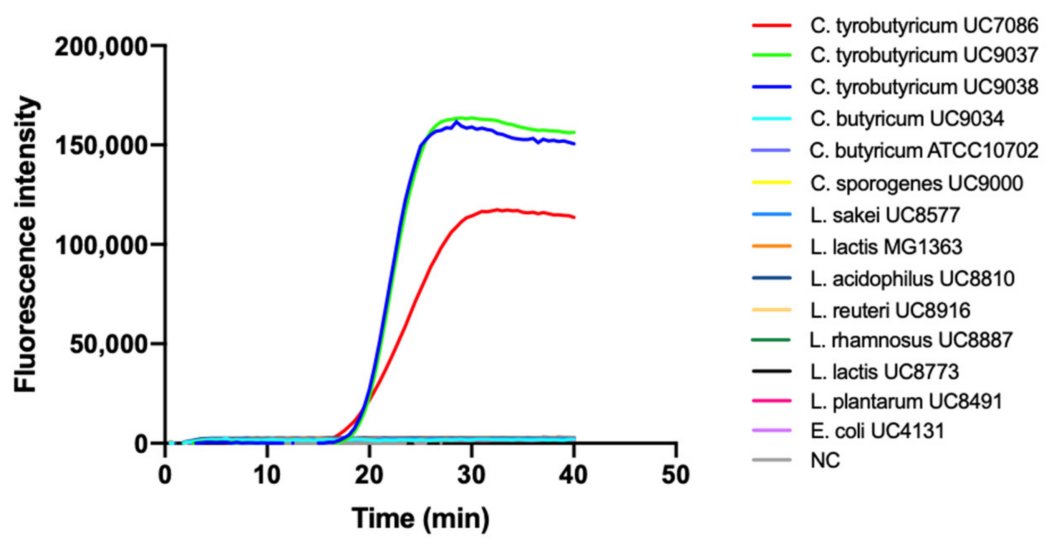

Figure 3. SYBR Green-based real-time fluorescent analysis of LAMP specificity based on genusspecific primer for C. tyrobutyricum. NC: negative control.

After the optimization of our test, we attempted to develop a simplified and instrumentfree approach with a naked-eye readout through a clear color change of the reaction samples. To this end, we exploited the $\mathrm{pH}$-sensitive LAMP strategy using the Cresol Red dye, which results in a pink-to-yellow color change upon target amplification, enabling the identification of positive samples by simple visual inspection [44-47].

After colorimetric LAMP, the reaction preserved the same sensibility displayed in the real-time fluorimetric detection, with a LoD of 2 spores/reaction. A representative result is shown in Figure 4. The colorimetric assay was able to identify the C. tyrobutyricum contamination, exhibiting a clear pink-to-yellow visible color change. Notably, the amplification reaction was effectively performed in the portable battery-operated device developed in our laboratories, revealing an opportunity for carrying out the entire method in point-of-care settings without the need for sophisticated instrumentations. 


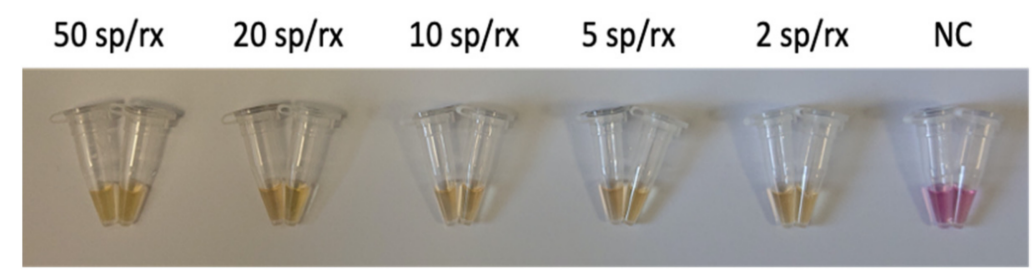

Figure 4. Representative colorimetric LAMP results for C. tyrobutyricum spore detection in water at different spore/reaction ( $\mathrm{sp} / \mathrm{rx}$ ) concentrations. NC: negative control. All experiments were performed in quadruplicate, each being repeated at least three times.

Once it was assessed that the colorimetric procedure was able to consistently detect the presence of $C$. tyrobutyricum spores even at a low concentration, we investigated its implementation in milk samples using artificially contaminated specimens and the same extraction procedure described above with no purification steps. In these tests, we took advantage of the high tolerance of the LAMP reaction to matrix contaminants [45]. As displayed in Figure 5, the experimental results showed the achievement of a LoD of 10 spores/reaction, with a $50 \%$ detection reliability for 5 spores/reaction. This indicates a minor loss of sensitivity in the case of real milk samples using the fast POC methodology.

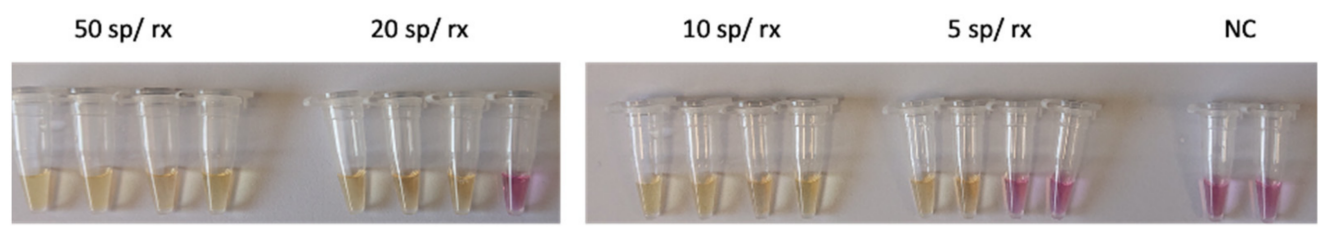

Figure 5. Representative colorimetric LAMP results for C. tyrobutyricum spore detection in milk samples. NC: negative control. All experiments were performed in quadruplicate, each being repeated at least three times.

Taking a further step, we explored the possibility of developing a semi-quantitative variant of our colorimetric test in order to address the industrial need for the quantification of $C$. tyrobutyricum levels in milk samples, which has practical relevance in the production process of hard cheese.

As explained in Figure 6, we exploited a visual detection scheme, using serial dilutions $(1: 1,1: 10,1: 100)$ of the milk samples, and we tested them through the colorimetric technique, obtaining three tubes relative to the different dilutions of each sample. Depending on the number of yellow tubes (positive tests), we can infer the level of spore contamination in a semi-quantitative way, i.e., a low (one positive tube), medium (two positive tubes), or high (three positive tubes) level of contamination, while noncontaminated samples have zero yellow tubes. Based on the sensitivity of our colorimetric method (10 sp/rx LoD), this strategy can roughly discriminate the $<10,10-100,100-1000$, or $>1000$ spore contamination ranges. A test experiment with milk samples spoiled with $0,20,200$, and 2000 spores/reaction confirmed the reliability of the devised strategy (Figure 6, right). 


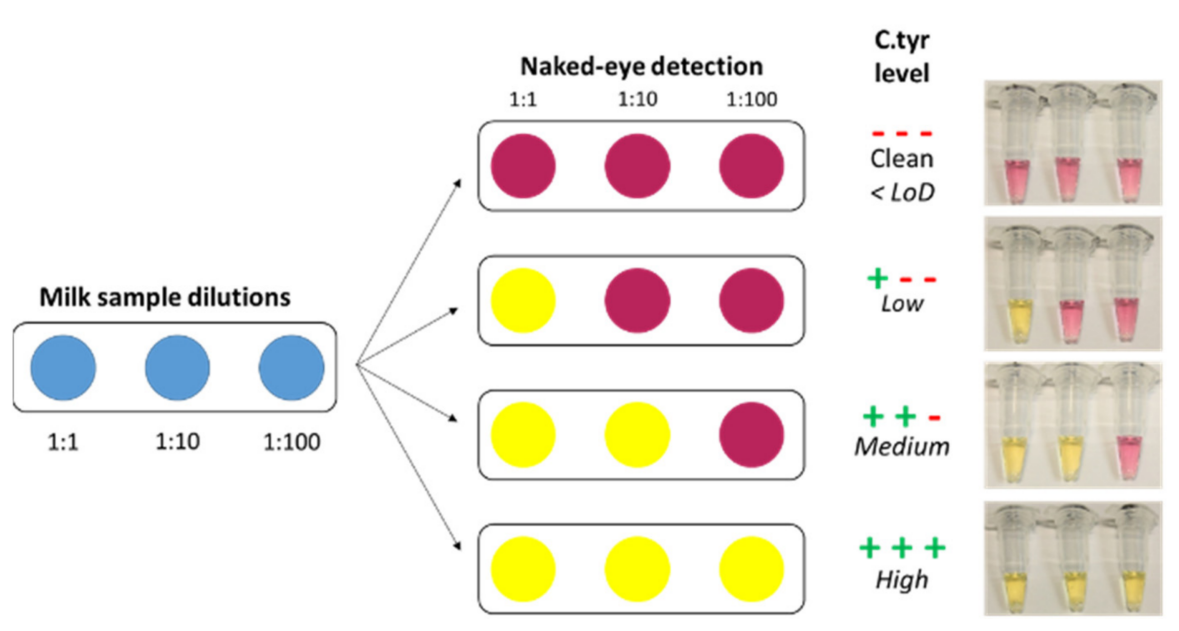

Figure 6. Semi-quantitative colorimetric test. Sample serial dilution allows for the identification of four different levels of contaminations. Zero yellow tubes: no contamination; one yellow tube: low contamination (ca. 10-100 spores); two yellow tubes: medium contamination (ca. 100-1000 spores); three yellow tubes: high contamination (ca. $>1000$ spores). A representative photo of a real experiment with $0,20,200,2000 \mathrm{sp} / \mathrm{rx}$ (from top to bottom) is shown on the right.

\section{Conclusions}

In this work, we reported the design and development of a fast POC strategy that combined a simple thermochemical DNA extraction, based on a fast purification-free "super-heating" step, with a colorimetric LAMP technique for the rapid naked-eye detection of C. tyrobutyricum spores in milk samples. The LAMP amplification, an efficient isothermal reaction operated in a simple and portable heating device, demonstrated enough sensitivity and specificity for quality control purposes. The direct colorimetric visual readout makes this approach potentially useful for on-field applications in the industry and hard cheese production chain.

Author Contributions: Conceptualization, P.S.C. and P.P.P.; methodology, P.C., F.G., C.C., D.B., F.L., P.S.C. and P.P.P.; investigation, P.C., F.G. and C.C.; resources, P.S.C. and P.P.P.; data curation, P.C., F.G. and P.P.P.; writing—original draft preparation, F.G. and P.P.P.; writing—review and editing, P.C., F.G., C.C., D.B., F.L., P.S.C. and P.P.P.; supervision, P.S.C. and P.P.P. All authors have read and agreed to the published version of the manuscript.

Funding: This research received no external funding.

Institutional Review Board Statement: Not applicable.

Informed Consent Statement: Not applicable.

Data Availability Statement: The data presented in this study are available on request from the corresponding author.

Acknowledgments: The authors are grateful to Marco Crepaldi and Claudio Lorini (IIT-EDL facility) for the device prototype development.

Conflicts of Interest: The authors declare no conflict of interest.

\section{References}

1. Podrzaj, L.; Burtscher, J.; Küller, F.; Domig, K.J. Strain-dependent cheese spoilage potential of Clostridium tyrobutyricum. Microorganisms 2020, 8, 1836. [CrossRef]

2. Garde, S.; Ávila, M.; Gaya, P.; Arias, R.; Nuñez, M. Sugars and organic acids in raw and pasteurized milk Manchego cheeses with different degrees of late blowing defect. Int. Dairy J. 2012, 25, 87-91. [CrossRef]

3. Bergère, J.L.; Lenoir, J. Cheese manufacturing accidents and cheese defects. In Cheesemaking: From Science to Quality Assurance; Intercept Limited: Andover, MA, USA, 2000; pp. 477-508. ISBN 1898298653.

4. Brändle, J.; Domig, K.J.; Kneifel, W. Relevance and analysis of butyric acid producing clostridia in milk and cheese. Food Control 2016, 67, 96-113. [CrossRef] 
5. Coulon, J.B.; Varignier, M.; Darne, D. Contamination butyrique du lait de vache: Étude dans les exploitations de Haute-Loire (1). INRA Prod. Anim. 1991, 4, 369-372. [CrossRef]

6. Ingham, S.C.; Hassler, J.R.; Tsai, Y.W.; Ingham, B.H. Differentiation of lactate-fermenting, gas-producing Clostridium spp. isolated from milk. Int. J. Food Microbiol. 1998, 43, 173-183. [CrossRef]

7. Klijn, N.; Nieuwenhof, F.F.J.; Hoolwerf, J.D.; Van der Waals, C.B.; Weerkamp, A.H. Identification of Clostridium tyrobutyricum as the causative agent of late blowing in cheese by species-specific PCR amplification. Appl. Environ. Microbiol. 1995, 61, $2919-2924$. [CrossRef]

8. Vissers, M. Modeling to Control Spores in Raw Milk; Wageningen University: Wageningen, The Netherlands, 2007; ISBN 978-908504-673-8.

9. Le Bourhis, A.G.; Doré, J.; Carlier, J.P.; Chamba, J.F.; Popoff, M.R.; Tholozan, J.L. Contribution of C. beijerinckii and C. sporogenes in association with C. tyrobutyricum to the butyric fermentation in Emmental type cheese. Int. J. Food Microbiol. 2007, 113, 154-163. [CrossRef] [PubMed]

10. Gómez-Torres, N.; Garde, S.; Peirotén, Á.; Ávila, M. Impact of Clostridium spp. on cheese characteristics: Microbiology, color, formation of volatile compounds and off-flavors. Food Control 2015, 56, 186-194. [CrossRef]

11. Bermúdez, J.; González, M.J.; Olivera, J.A.; Burgueño, J.A.; Juliano, P.; Fox, E.M.; Reginensi, S.M. Seasonal occurrence and molecular diversity of clostridia species spores along cheesemaking streams of 5 commercial dairy plants. J. Dairy Sci. 2016, 99, 3358-3366. [CrossRef] [PubMed]

12. Lycken, L.; Borch, E. Characterization of Clostridium spp. isolated from spoiled processed cheese products. J. Food Prot. 2006, 69, 1887-1891. [CrossRef] [PubMed]

13. Reindl, A.; Dzieciol, M.; Hein, I.; Wagner, M.; Zangerl, P. Enumeration of clostridia in goat milk using an optimized membrane filtration technique. J. Dairy Sci. 2014, 97, 6036-6045. [CrossRef]

14. Garde, S.; Arias, R.; Gaya, P.; Nuñez, M. Occurrence of Clostridium spp. in ovine milk and Manchego cheese with late blowing defect: Identification and characterization of isolates. Int. Dairy J. 2011, 21, 272-278. [CrossRef]

15. Nishihara, M.; Takahashi, H.; Sudo, T.; Kyoi, D.; Kawahara, T.; Ikeuchi, Y.; Fujita, T.; Kuda, T.; Kimura, B.; Yanahira, S. Multilocus variable-number of tandem repeat analysis (MLVA) for Clostridium tyrobutyricum strains isolated from cheese production environment. Int. J. Food Microbiol. 2014, 190, 61-65. [CrossRef] [PubMed]

16. Bassi, D.; Puglisi, E.; Cocconcelli, P.S. Understanding the bacterial communities of hard cheese with blowing defect. Food Microbiol. 2015, 52, 106-118. [CrossRef] [PubMed]

17. Bassi, D.; Fontana, C.; Gazzola, S.; Pietta, E.; Puglisi, E.; Cappa, F.; Cocconcelli, P.S. Draft genome sequence of Clostridium tyrobutyricum strain UC7086, isolated from Grana Padano cheese with late-blowing defect. Genome Announc. 2013, 1. [CrossRef]

18. Cocolin, L.; Innocente, N.; Biasutti, M.; Comi, G. The late blowing in cheese: A new molecular approach based on PCR and DGGE to study the microbial ecology of the alteration process. Int. J. Food Microbiol. 2004, 90, 83-91. [CrossRef]

19. Morandi, S.; Cremonesi, P.; Silvetti, T.; Castiglioni, B.; Brasca, M. Development of a triplex real-time PCR assay for the simultaneous detection of Clostridium beijerinckii, Clostridium sporogenes and Clostridium tyrobutyricum in milk. Anaerobe 2015, 34, 44-49. [CrossRef]

20. Mato Rodriguez, L.; Alatossava, T. Effects of copper on germination, growth and sporulation of Clostridium tyrobutyricum. Food Microbiol. 2010, 27, 434-437. [CrossRef] [PubMed]

21. Bassi, D.; Cappa, F.; Cocconcelli, P.S. A combination of a SEM technique and X-ray microanalysis for studying the spore germination process of Clostridium tyrobutyricum. Res. Microbiol. 2009, 160, 322-329. [CrossRef] [PubMed]

22. Langó, Z.; Heinonen-Tanski, H. Occurrence of Clostridium tyrobutyricum in cattle slurry and fresh forage grasses. Bioresour. Technol. 1995, 53, 189-191. [CrossRef]

23. Zucali, M.; Bava, L.; Colombini, S.; Brasca, M.; Decimo, M.; Morandi, S.; Tamburini, A.; Crovetto, G.M. Management practices and forage quality affecting the contamination of milk with anaerobic spore-forming bacteria. J. Sci. Food Agric. 2015, 95, 1294-1302. [CrossRef] [PubMed]

24. Ávila, M.; Gómez-Torres, N.; Hernández, M.; Garde, S. Inhibitory activity of reuterin, nisin, lysozyme and nitrite against vegetative cells and spores of dairy-related Clostridium species. Int. J. Food Microbiol. 2014, 172, 70-75. [CrossRef] [PubMed]

25. Elwell, M.W.; Barbano, D.M. Use of microfiltration to improve fluid milk quality. J. Dairy Sci. 2006, 89 (Suppl. S1), E20-E30. [CrossRef]

26. Klantschitsch, T. Influence of microfiltration on the quality of semi-hard cheese from raw milk with particular emphasis on Clostridium tyrobutyricum spores. Diss. Techn. Wiss. ETH Zürich Nr. 1999. [CrossRef]

27. Gómez-Torres, N.; Ávila, M.; Gaya, P.; Garde, S. Prevention of late blowing defect by reuterin produced in cheese by a Lactobacillus reuteri adjunct. Food Microbiol. 2014, 42, 82-88. [CrossRef]

28. Carmen Martínez-Cuesta, M.; Bengoechea, J.; Bustos, I.; Rodríguez, B.; Requena, T.; Peláez, C. Control of late blowing in cheese by adding lacticin 3147-producing Lactococcus lactis IFPL 3593 to the starter. Int. Dairy J. 2010, 20, 18-24. [CrossRef]

29. D'Incecco, P.; Pellegrino, L.; Hogenboom, J.A.; Cocconcelli, P.S.; Bassi, D. The late blowing defect of hard cheeses: Behaviour of cells and spores of Clostridium tyrobutyricum throughout the cheese manufacturing and ripening. LWT Food Sci. Technol. 2018, 87, 134-141. [CrossRef]

30. Rossen, L.; Nørskov, P.; Holmstrøm, K.; Rasmussen, O.F. Inhibition of PCR by components of food samples, microbial diagnostic assays and DNA-extraction solutions. Int. J. Food Microbiol. 1992, 17, 37-45. [CrossRef] 
31. Bogovič Matijašić, B.; Koman Rajšp, M.; Perko, B.; Rogelj, I. Inhibition of Clostridium tyrobutyricum in cheese by Lactobacillus gasseri. Int. Dairy J. 2007, 17, 157-166. [CrossRef]

32. Stadhouders, J.; van den Berg, G. Use of Lysozyme for the Prevention of Butyric Acid Fermentation in Gouda Cheese. Limited Effect of the Enzyme. In International Dairy Federation MILK the Vital Force; Springer: Berlin/Heidelberg, Germany, $1986 ;$ p. 77.

33. Stadhouders, J. Prevention of butyric acid fermentation by the use of nitrate. Bull. Int. Dairy Fed. 1990, 251, 40-46.

34. Koréneková, B.; Kottferová, J.; Korének, M. The fate of added nitrate used in the manufacture of Emmental cheese. Food Addit. Contam. 2000, 17, 373-377. [CrossRef] [PubMed]

35. Bassi, D.; Cappa, F.; Cocconcelli, P.S. Array-based transcriptional analysis of Clostridium sporogenes UC9000 during germination, cell outgrowth and vegetative life. Food Microbiol. 2013, 33, 11-23. [CrossRef] [PubMed]

36. López-Enríquez, L.; Rodríguez-Lázaro, D.; Hernández, M. Quantitative detection of Clostridium tyrobutyricum in milk by real-time PCR. Appl. Environ. Microbiol. 2007, 73, 3747-3751. [CrossRef]

37. Lavilla, M.; Marzo, I.; De Luis, R.; Perez, M.D.; Calvo, M.; Sánchez, L. Detection of Clostridium tyrobutyricum spores using polyclonal antibodies and flow cytometry. J. Appl. Microbiol. 2010, 108, 488-498. [CrossRef]

38. Bergère, J.L.; Sivela, S. Detection and enumeration of clostridial spores related to cheese quality-classical and new methods. Bull. Int. Dairy Fed. 1990, 251, 18-23.

39. Ivy, R.A.; Wiedmann, M. Clostridium: Clostridium tyrobutyricum. In Encyclopedia of Food Microbiology, 2nd ed.; Elsevier Inc.: Amsterdam, The Netherlands, 2014; pp. 468-473. ISBN 9780123847331.

40. Fischer, M.; Zhu, S.; de Ree, E. Culture Media for the Detection and Enumeration of Clostridia in Food. In Handbook of Culture Media for Food and Water Microbiology; Royal Society of Chemistry: London, UK, 2011; pp. 66-89, Chapter 3.

41. Herman, L.M.F.; De Block, J.H.G.E.; Waes, G.M.A.V.J. A Direct PCR Detection Method for Clostridium tyrobutyricum Spores in up to 100 Milliliters of Raw Milk. Appl. Environ. Microbiol. 1995, 61, 4141-4146. [CrossRef] [PubMed]

42. Herman, L.; De Block, J.; van Renterghem, R. Isolation and detection of Clostridium tyrobutyricum cells in semi-soft and hard cheeses using the polymerase chain reaction. J. Dairy Res. 1997, 64, 311-314. [CrossRef]

43. Esteban, M.; Marcos, P.; Horna, C.; Galan-Malo, P.; Mata, L.; Pérez, M.D.; Calvo, M.; Sánchez, L. Evaluation of methods for DNA extraction from Clostridium tyrobutyricum spores and its detection by qPCR. J. Microbiol. Methods 2020, 169. [CrossRef] [PubMed]

44. Tanner, N.A.; Zhang, Y.; Evans, T.C. Visual detection of isothermal nucleic acid amplification using pH-sensitive dyes. Biotechniques 2015, 58, 59-68. [CrossRef]

45. Tatulli, G.; Cecere, P.; Maggioni, D.; Galimberti, A.; Pompa, P.P. A Rapid Colorimetric Assay for On-Site Authentication of Cephalopod Species. Biosensors 2020, 10, 190. [CrossRef] [PubMed]

46. Jaroenram, W.; Cecere, P.; Pompa, P.P. Xylenol orange-based loop-mediated DNA isothermal amplification for sensitive naked-eye detection of Escherichia coli. J. Microbiol. Methods 2019, 156, 9-14. [CrossRef] [PubMed]

47. Cibecchini, G.; Cecere, P.; Tumino, G.; Morcia, C.; Ghizzoni, R.; Carnevali, P.; Terzi, V.; Pompa, P.P. A Fast, Naked-Eye Assay for Varietal Traceability in the Durum Wheat Production Chain. Foods 2020, 9, 1691. [CrossRef] [PubMed] 